\title{
Solving Unit Commitment Problem in Regulated and Deregulated Power Systems Using Particle Swarm Algorithm
}

\author{
Sahar.S.Kaddah \\ Department of electrical Power Engineering \\ University of Mansoura \\ skaddah@mans.edu.eg
}

\author{
Ragab.A. Elsehiemy \\ Department of electrical Power Engineering \\ University of Kafr elshiekh \\ elsehiemy@yahoo.com
}

\author{
Alaa .A. Zaky \\ Department of electrical Power Engineering \\ University of Kafr elshiekh \\ alaazaky91@yahoo.com
}

\begin{abstract}
An important criterion in power system operation is to meet the power demand at minimum fuel cost using an optimal mix of different power plants. Moreover, in order to supply electric power to customers in a secured and economic manner, thermal unit commitment is considered to be one of the best available options. It is thus recognized that the optimal unit commitment of thermal systems results in a great saving for electric utilities. The unit commitment has been identified for this paper work. The complexity of the UC problems grows exponentially to the number of generating units especially by applying the deregulated rules in power system. Where in this environment the objective function is maximizing the profit while satisfying the regular unit commitment constrains with addition of new constrains such as bilateral and multilateral contracts. The formulation of unit commitment has been discussed and the solution is obtained by an algorithm based on Particle Swarm Optimization technique the proposed algorithm is implemented in MATLAB environment.
\end{abstract}

Index Terms - particle swarm optimization (PSO), unit commitment, optimization methods, power generation dispatch.

\section{INTRODUCTION}

The regular unit Commitment is the problem of determining the schedule of generating units at minimum system production cost during the period while simultaneously satisfying the load demand, spinning reserve, ramp constrains and the operational constrains of the individual unit $[1,2]$. In an electric power system, the total load on the system will generally be higher during the daytime and early evening when industrial loads are high, lights are on, and so forth, and lower during the late evening and early morning when most of the population is asleep[3]-[6]. In addition, the use of electric power has a weekly cycle, the load being lower over weekend days than weekdays. So it's not economical to commit enough units to cover the maximum system load and leave them running it is necessary to commit some units and decommit some other to cover the load demand with a suitable reserve to save cost Unit commitment (UC) is a nonlinear mixed integer optimization problem to schedule the operation of the generating units at minimum operating cost while satisfying the demand and other 
equality and inequality constrains. The UC problem has to determine the on/off state of the generating units at each hour of the planning period and optimally dispatch the load among the committed units. UC is the most significant optimization task in the operation of the power systems. Solving the UC problem for large power systems is computationally expensive. The complexity of the UC problems grows exponentially to the number of generating units.

Several solution strategies have been proposed to provide quality solutions to the UC problem and increase the potential savings of the power system operation. These strategies include deterministic and stochastic search approaches. Deterministic approaches include the priority list method, dynamic programming, the branch and bound methods, mixed integer programming (MIP),interior point optimization and Lagrangian Relaxation[7]-[15]. Although these methods are simple and fast, they suffer from numerical convergence and solution quality problems. The stochastic search algorithms such as particle swarm optimization [16, 17], genetic algorithms [18, 19], evolutionary programming, simulated annealing [20], ant colony optimization [21] and tabu search [22] are able to overcome the shortcomings of traditional optimization techniques. These methods can handle complex nonlinear constraints and provide high quality solutions. This formulation drastically reduces the number of decision variables and hence can overcome the shortcomings of stochastic search algorithms for UC problems. Due to simplicity and less parameter tuning, particle swarm optimization is used for solving the unit commitment problem. In this paper we have to study the algorithm of particle Swarm optimization and formulate the algorithm for solving unit commitment for deregulated power system.

\section{NOMENCLATURE}

$F\left(P_{i t}\right)$ Production cost of unit $i$ in time period $t(\$)$.

$S U C_{i t}$ Start-up cost for unit $i$ in time period $t(\$)$.

TC Total cost of GENCO (\$).

$\mathrm{CH}_{\mathrm{i}} \quad$ The cold start hour (hr) at unit $i$.

$C S C_{i} \quad$ The unit's cold start-up cost at unit $i$ (\$).

$H S C_{i} \quad$ The unit's hot start-up cost at unit $i$ (\$).

$D_{t}^{\prime} \quad$ Forecasted demand at hour $\mathrm{t}(\mathrm{MW})$.

$N \quad$ Number of generator units.

Nt A chosen number of intervals.

$P_{i \min } \quad$ Minimum limit of generator i (MW).

$P_{i t} \quad$ Power generation of unit i at hour $\mathrm{t}(\mathrm{MW})$.

$P_{i \max } \quad$ Maximum limit of generator $i(\mathrm{MW})$.

$R_{i t} \quad$ Reserve generation of unit $i$ at hour $t$ (MW).

$S D C_{i t} \quad$ Shut-down cost of unit $i$ at time period $t(\$)$.

$S P_{t} \quad$ Forecasted spot price at hour $t(\$)$.

$S R_{t}^{\prime} \quad$ Forecasted reserve at hour $t(\mathrm{MW})$.

$T \quad$ Number of hours

$\mathrm{T}_{\mathrm{i}}^{\text {off }} \quad$ Minimum off-time of unit $i(\mathrm{hr})$.

$\mathrm{T}_{\mathrm{i}}^{\text {on }} \quad$ Minimum-on time of unit $i(\mathrm{hr})$.

$\mathrm{U}_{\mathrm{it}} \quad$ On/off status of generator $\mathrm{i}$ at hour $\mathrm{t}$.

$\mathrm{X}_{(\mathrm{i}, \mathrm{t}-1)}^{\text {on }}$ Time duration for which unit $i$ has been ontime at hour $t(\mathrm{hr})$.

$\mathrm{X}_{(\mathrm{i}, \mathrm{t}-1)}^{\mathrm{off}}$ Time duration for which unit $i$ has been offtime at hour $t(\mathrm{hr})$.

$R P_{t} \quad$ Forecasted reserve price at hour $t$.

$r \quad$ Probability that the reserve is called and generated.

PF Profit of GENCO (\$).

$R V \quad$ Revenue of GENCO (\$).

$x_{k, t} \quad$ Specifies the consecutive time that the unit has been on (+) or off (-) at the end of the hour $t$. 
$\mathrm{S}_{\mathrm{k}}\left(x_{k, t}\right) \quad$ Start-up cost, which for thermal units depends on the prevailing temperature of the boilers

$K \quad$ Represent the generator number

$P_{k}^{\max } \quad$ Maximum output of generator $\mathrm{k}$

$P_{k}^{\text {min }} \quad$ Minimum output of generator k

$t_{k}^{\mathrm{dn}} \quad$ Time that generator must stay off when shutdown

$t_{k}^{\text {up }}$ Time that generator must stay on when start up

$v_{i d}^{(t n)} \quad$ Velocity of particle $i$ at iteration $t n$.

$x_{i d}^{(t n)} \quad$ Current position of particle $i$ at iteration $t n$.

PBUC Profit based unit commitment

$W \quad$ Inertia weight factor.

tn Number of iterations .

$\mathrm{n} \quad$ Number of particles in a group .

$\mathrm{m} \quad$ Number of members in a particle .

$C l$ and $c_{2}$ Acceleration constant of PSO.

$\operatorname{rand}_{1}(\cdot)$ And $\operatorname{rand}_{2}(\cdot)$ Random numbers between 0 and 1.

iter $_{\max }$ and iter: Maximum the current number of iterations.

\section{PARTICLE SWARM OPTIMIZATION}

Particle swarm optimization is a computing technique introduced by Kennedy and Eberhart in 1995, which was inspired by the social behavior of bird flocking or fish schooling (Reynolds, 1987). They theorize that the process of cultural adaptation can be summarized in terms of three principles: evaluate, compare and imitate. An organism, a bird in PSO, evaluates its neighbors, compares itself to others in the population and then imitates only those neighbors who are superior. PSO is inspired by particles moving around in the search space. The individuals in a PSO thus have their own positions and velocities. These individuals are denoted as particles. Traditionally, PSO has no crossover between individuals, has no mutation, and particles are never substituted by other individuals during the run . The update of the particles is accomplished to calculate a new velocity for each particle (potential solution) based on its previous velocity $\left(v_{i d}\right)$, the particle's location at which the best fitness so far has been achieved ( pbest $\left._{i d}\right)$, and the population global location $\left(\right.$ gbest $\left._{d}\right)$ at which the best fitness so far has been achieved. Then, each particle's position in the solution hyperspace is updated as shown in figure 1 . The modified velocity and position of each particle can be calculated using the current velocity and distance from pbest $_{i d}$ to gbest $_{d}$ as shown in the following equations:

$$
\begin{aligned}
v_{i d}^{(t n+1)}= & w \cdot v_{i d}^{(t n)}+c_{1} \cdot \operatorname{rand}_{1}(.) \cdot\left(\text { pbest }_{i d}-x_{i d}^{(t n)}\right) \\
& +c_{2} \cdot \operatorname{rand}_{2}(.) \cdot\left(\text { gbest }_{d}-x_{i d}^{(t n)}\right)
\end{aligned}
$$

$x_{i d}^{(t n+1)}=x_{i d}^{(t n)}+v_{i d}^{(t n+1)}$

Velocity of particle $\mathrm{i}$ at iteration $\mathrm{t}$; in d-dimensional space is limited by: $v_{d, \text { min }}<v_{i d}^{(t n)}<v_{d, \text { max }}$, Appropriate selection of inertia weight in (1) provides a balance between global and local explorations. As originally developed, often decreases linearly during a run. In general, the inertia weight factor $(w)$ is set to the following equation:

$w=w_{\max }-\frac{w_{\max }-w_{\min }}{\text { iter }_{\max }}$ iter

The velocity of particle $\mathrm{i}$ in d-dimensional space is limited by some maximum value, $v_{d, \max }$. This limit enhances the local exploration of the problem space and it realistically simulates the incremental changes of human learning. To ensure uniform velocity through all dimensions, the maximum velocity in the d-dimension is presented as:

$$
v_{d, \max }=\frac{x_{d i, \max }-x_{d i, \min }}{N t}
$$




\section{UC PROBLEM FORMULATION}

\section{A. UC in regulated power system}

Unit commitment is an optimization problem of determining the schedule of generating units within a power system with a number of constraints [23, 24]. The objective of the UC problem is to minimize the total operating costs subjected to a set of system and unit constraints over the scheduling horizon as shown in figure 2 .

$$
\begin{aligned}
& T C=\sum_{i}^{N} \sum_{t}^{T} \cdot F\left(P_{i t}\right) \mathrm{U}_{\mathrm{it}}+S U C_{i t} \cdot\left(1-\mathrm{U}_{\mathrm{it}}\right) \cdot \mathrm{U}_{\mathrm{it}} \\
& +S D C_{i t} \cdot\left(1-\mathrm{U}_{\mathrm{it}}\right) \cdot \mathrm{U}_{\mathrm{i},(\mathrm{t}-1)}
\end{aligned}
$$

The generator fuel-cost function can be expressed as:

$$
F\left(P_{i t}\right)=a_{i}+b_{i} \cdot P_{i t}+c_{i} \cdot P_{i t}^{2}
$$

where, $\mathrm{a}_{\mathrm{i}}, \mathrm{b}_{\mathrm{i}}$ and $\mathrm{c}_{\mathrm{i}}$ are the unit cost coefficients. Subject to:

1) Demand Constraint:

$$
\sum_{i=1}^{N} P_{i t} U_{i t} \leq D_{t}^{\prime} \quad \mathrm{t}=1, \ldots, \mathrm{T}
$$

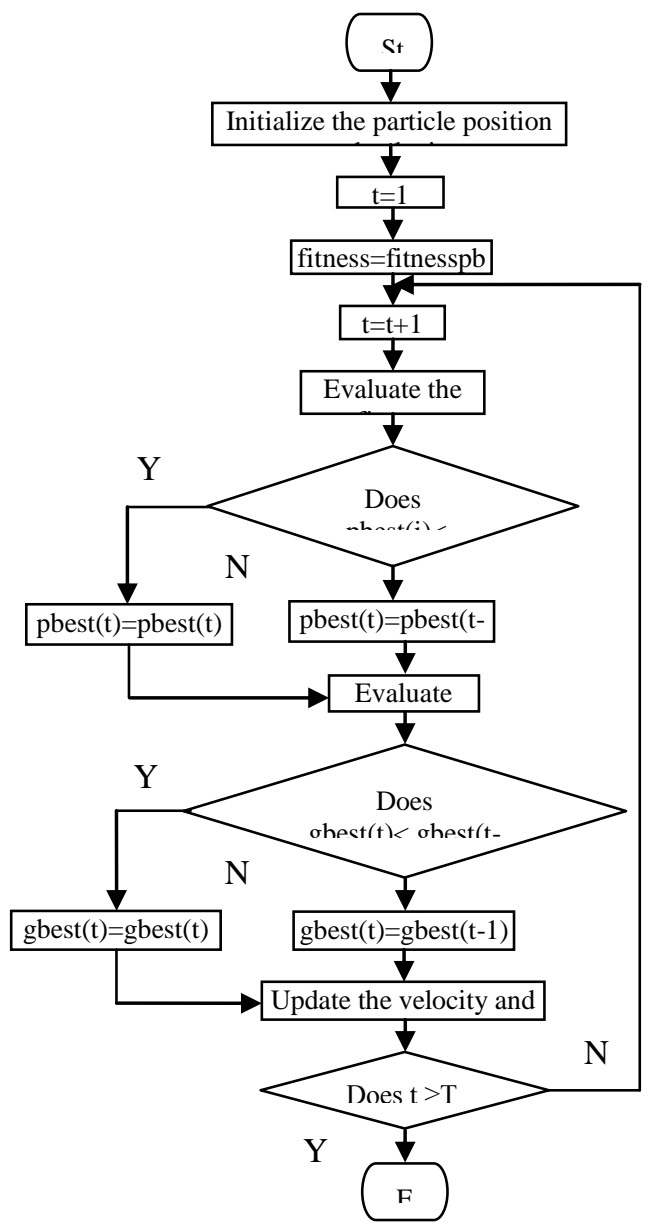

Fig. 1 flow chart of particle swarm optimization
2) Reserve Constraint:

$$
\sum_{i=1}^{N} R_{i t} U_{i t} \leq S R_{t}^{\prime} \quad \mathrm{t}=1, \ldots, \mathrm{T}
$$

.Power generation and reserve limits:

$$
P_{i \text { min }} \leq P_{(i, t)} \leq P_{i \text { max }} \quad \mathrm{i}=1, \ldots, \mathrm{N}
$$

$$
0 \leq R_{(i, t)} \leq P_{i \max }-P_{i \text { min }} \mathrm{i}=1, \ldots, \mathrm{N}
$$

3) Minimum Up and Down time Constraints:

$$
\left[\mathrm{X}_{(\mathrm{i}, \mathrm{t}-1)}^{\mathrm{on}}-\mathrm{T}_{\mathrm{i}}^{\mathrm{on}}\right]\left[\mathrm{U}_{(\mathrm{i}, \mathrm{t}-\mathrm{l})}-\mathrm{U}_{\mathrm{it}}\right] \geq 0
$$

$$
\left[\mathrm{X}_{(\mathrm{i}, \mathrm{t}-1)}^{\mathrm{off}}-\mathrm{T}_{\mathrm{i}}^{\mathrm{off}}\right]\left[\mathrm{U}_{\mathrm{it}}-\mathrm{U}_{(\mathrm{i}, \mathrm{t}-1)}\right] \geq 0
$$

Start-up cost is calculated from (13) and shown in figure 3

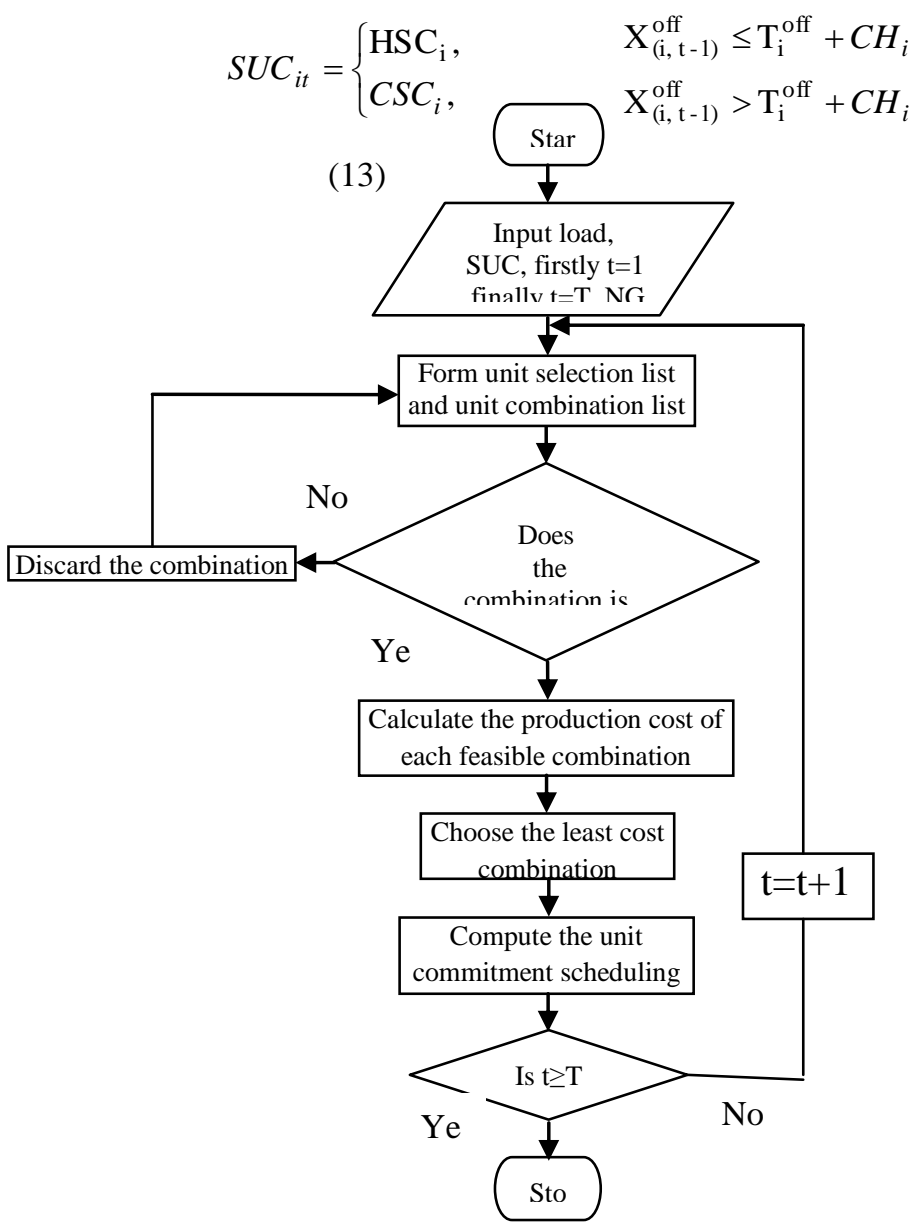

Fig. 2 flow chart to solve unit commitment problem 


\section{B. UC in deregulated power system}

Deregulation in power sector increases the efficiency of electricity production and distribution, offer lower prices, higher quality, a secure and a more reliable product and this affect UC problem. UC schedule depends on the market price in the deregulated market. In deregulated environment utilities are not required to meet the demand. GENCO can consider a schedule that produce less than the predicted load demand and reserve but creates maxi- mum profit. More number of units are committed when the market price is higher. When more number of generating units are brought online more power is generated and participated in the deregulated market to get maximum profit. for the commitment decisions made by the Independent System Operator (ISO). The ISO resembles very much the operation of a power generating utility under regulation. The ISO manages the transmission grid, controls the dispatch of generation, oversees the reliability of the system, and administers congestion protocols [24]. The ISO is a non-profit organization. Its economic objective is to maximize social welfare, which is obtained by minimizing the costs of reliably supplying the aggregate load. Under deregulation, the UCP for an electric power producer will require a new formulation that includes the electricity market in the model. Starting from the late eighties, the transition towards the wholesale electric energy market, taking place in most countries in the world, demanded for a reconsideration of the unit commitment problem.

As deregulation [25] is being implemented in various regions of the world, the traditional unit commitment problem continues to remain applicable for the commitment decisions made by the Independent System Operator (ISO). The ISO resembles very much the operation of a power generating utility under regulation. The ISO manages the transmission grid, controls the dispatch of generation, oversees the reliability of the system, and administers congestion protocols [26]. The ISO is a non-profit organization. Its economic objective is to maximize social welfare, which is obtained by minimizing the costs of reliably supplying the aggregate load. Under deregulation, the UCP for an electric power producer will require a new formulation that includes the electricity market in the model. The main difficulty here is that the spot price of electricity is no longer predetermined but set by open competition. Thus far, the hourly spot prices of electricity have shown evidence of being highly volatile. The unit commitment decisions are now harder and the modeling of spot prices becomes very important in this new operating environment.

In fact, generation companies (GENCOs), operating in an open electricity market, are no longer bound to serve a local load, but aim at maximizing their own profits. In the pool-based electricity market, every GENCO submits bid- ding price function to the independent system operator (ISO) for every hour of the planning horizon. The ISO uses bidding price function and forecasted demand to determine market clearing price (MCP) and hourly generation outputs by maximizing the total surplus of generators and consumers. In the market, ISO would be forecasting the demand and the price for the next day/hour. The GENCOs will send its bidding to the ISO, depending upon the demand and its generator coefficients. The ISO will accept and select the bidder whose price is less than or equal to its expected price (forecasted price). If the bidder's price is more than the forecasted one, then ISO will fix the forecasted price as MCP. If any of the GENCOs fix the price below the forecasted price, then the ISO will fix the lowest price as the MCP. However, each company's bidding differs from others, depending 
upon their generator coefficient which is confidential [27] and therefore ISO has to be very judicious for the equal participation of all GENCOs in the competing pool.

Generally the maximization of profit is different from the minimizing cost because GENCOs no longer have the obligation to serve. They may choose to generate less than the demand, which allows more flexibility in UC schedules. However, in certain markets such as New Zealand Energy Market, unit commitment is the sole responsibility of individual GENCOs. In these markets the GENCOs use their bidding strategies and submit single part bids to the ISO, for fully satisfying the forecasted load without any flexibility [28]. These GENCOs in advance ensure that optimal dispatch for the forecasted price, while submitting their bids. Hence, the information on optimal production obtained, is still valuable when making bidding strategies. These strategies may however include uncertainty in price, the behavior of other participants and risk averseness, of the GENCOs.

Therefore a cumulative bid for all units owned by GENCOs may also be submitted to the pool. Therefore, ISO will look vigilantly into both single part bid and cumulative bid, before making the MCP, in case of uncertainties. But only after the market is cleared, each GENCO would know their individual demand in the spot market. Now, based on these demands, the GENCOs can again carryout selfcommitment to obtain optimal decisions. This is when the demand constraints become relevant for competitive GENCOs. This makes the UC similar to the traditional power systems where the objective is to minimize system cost to meet system demand.

Considering the Singapore market, the GENCOs will participate in the market operations and submit their biddings depending upon the forecasted load and price, by the market operator. The whole- sale spot market prices, reflect the least-cost market solution to the dispatch of energy and the provision of reserve and regulation. In general, this means that each generator that submits an offer below the market price will be dispatched and a generator that submits an offer above the market price will not be dispatched. The market price for energy that dispatchable generators receive is a nodal price, which may vary according to the location on the network of the node, to which the dispatchable generator has been assigned [29]. The important role of the wholesale electricity market is to determine the competitive electricity prices for the benefit of consumers, in the contestable market. Therefore, each generator competes to bid below or at least equal to the forecasted price, so that the unit should not incur a loss and may choose to generate less than the demand.

According to this, the GENCOs will dispatch the load in an hour if they get the profit in that hour. Each generator that participates in the markets or that causes or permits electricity to be conveyed into, through or out of the ISO-controlled grid, shall operate and maintain its generation facilities and equipment in a manner that is consistent with the reliable operation of the ISO-controlled grid. They shall assist the ISO in the discharge of its responsibilities related to reliability [30]. Based on the above mentioned activities of GENCOs.

UC choices are therefore driven by the expected behaviour of market prices over the time rather than by the forecasted load levels. A number of technical papers witness the renewed interest in the UC problem with the aim of developing optimal bidding strategies for the market.

The objective function is given by the sum over the hours in the interval $[0, T]$ of the revenue minus the cost. The revenue is obtained from supplying the bilateral contracts and by selling to the power pool at 
a price of $m_{t}$ per MWH the surplus energy $E_{t}$ (if any) produced in each hour $t$. The cost includes the cost of producing the energy, buying shortfalls (if needed) from the power pool, and the startup costs. Defining the supply amount stipulated under the bilateral contract by $l_{t}(\mathrm{MWH})$ and by $R(\$ / \mathrm{MWH})$ the price, the objective function (maximum total profit) is given by

$\operatorname{Max}$

$P F=R V-T C$

(14)

$\mathrm{CF}_{\mathrm{k}}(p)=a_{k}+b_{k} p+c_{k} p^{2}$ (15)

$\underset{v_{k, t}, P_{k, t}, E_{t}}{\operatorname{Max}}\left\{\sum_{t=1}^{T}\left\{l_{t} R-m_{t} E_{t}-\sum_{k=1}^{M}\left[\mathrm{CF}_{\mathrm{k}}\left(P_{k, t}\right)+S_{k}\left(x_{k, t}\right)\left(1-v_{k, t-1}\right)\right] v_{k, t}\right\}\right\}$ (16)

A positive value of $E_{t}$ indicates that $E_{t}$ megawatts hour are bought from the power pool and a negative value indicates that $-E_{t}$ megawatts hour are sold to the pool. Since the quantity $l_{t} R$ is a constant, the optimization problem reduces to:

$$
\underset{v_{k, t}, P_{k, t}, E_{t}}{\operatorname{Max}}\left\{\sum_{t=1}^{T}\left\{-m_{t} E_{t}-\sum_{k=1}^{M}\left[\mathrm{CF}_{\mathrm{k}}\left(P_{k, t}\right)+S_{k}\left(x_{k, t}\right)\left(1-v_{k, t-1}\right)\right] v_{k, t}\right\}\right\}
$$

subject to the following constraints

(for $t=1, \ldots, T$ and $k=1, \ldots, M$ )

Load:

$$
E_{t}+\sum_{k=1}^{M} v_{k, t} P_{k, t}=l_{t}
$$

Capacity limits: $\quad v_{k, t} P_{k}^{\min } \leq P_{k, t} \leq v_{k, t} P_{k}^{\max }$
Minimum down time:

$v_{k, t} \leq 1-\mathrm{I}\left(-t_{k}^{d n}+1 \leq x_{k, t-1} \leq-1\right)$

Minimum up time: $\quad v_{k, t} \geq \mathrm{I}\left(1 \leq x_{k, t-1} \leq t_{k}^{u p}-1\right)$

where $\mathrm{I}(x)= \begin{cases}0 & \text { if } x \text { is false } \\ 1 & \text { if } x \text { is true }\end{cases}$

$$
P_{k, t} \geq 0 \text { and } E_{t} \text { unrestricted in sign } v_{k, t}=\{0,1\}
$$

After substituting in the objective function the value of $E_{t}=l_{t}-\sum_{k=1}^{M} v_{k, t} P_{k, t}$, obtained from Equation 18, we re-write Equation 16 as follows:

$\operatorname{Max}_{v_{k, t}, P_{k, t}, E_{t}}\left\{\sum_{t=1}^{T}\left\{-m_{t}\left[l_{t}-\sum_{k=1}^{M} P_{k, t} v_{k, t}\right]-\sum_{k=1}^{M}\left[\mathrm{CF}_{\mathrm{k}}\left(P_{k, t}\right)+S_{k}\left(x_{k, t}\right)\left(1-v_{k, t-1}\right)\right] v_{k, t}\right\}\right\}$ (22)

which after removing constant terms is equivalent to: $\operatorname{Max}_{v_{k, t}, P_{k, t}}\left\{\sum_{t=1}^{T}\left\{\sum_{k=1}^{M}\left[m_{t} P_{k, t}-\mathrm{CF}_{\mathrm{k}}\left(P_{k, t}\right)+S_{k}\left(x_{k, t}\right)\left(1-v_{k, t-1}\right)\right] v_{k, t}\right\}\right\}$

Subject to the operating constraints. Because the constraints (18) to (21) refer to individual units only, the advantage of Equation 23 is that the objective function is now separable by individual units. The optimal solution can be found by solving $M$ decoupled sub-problems. Thus, the sub-problem $\mathrm{D}_{\mathrm{k}}$ for the $\quad k^{\text {th }} \quad$ unit $\quad(k=1, . ., M) \quad$ is.

$\underset{v_{k, t}, P_{k, t}}{\operatorname{Max}}\left\{\sum_{t=1}^{T}\left[m_{t} P_{k, t}-\mathrm{CF}_{\mathrm{k}}\left(P_{k, t}\right)+S_{k}\left(x_{k, t}\right)\left(1-v_{k, t-1}\right)\right] v_{k, t}\right\}$

\section{CASE STUDIES}

In this paper there are two case studies which are 3unit system and 10- unit system and there data are as 
follow .Both cases are tested for regulated and

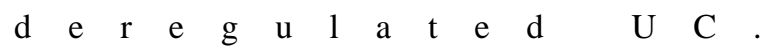
Case1: 3-unit 12-hour system

System data are listed in table 1 and the load curve is shown in figure 3.The 3-unit 12-hour system has a total capacity of $1200 \mathrm{MW}$ and peak load and minimum load of $1100 \mathrm{MW}$ and $170 \mathrm{MW}$ ,respectively.
Case2: 10-unit 24-hour test system

The data for this case are listed in table 4 and the load curve of this case is shown in figure 4 this system has a total capacity of $1662 \mathrm{MW}$ and peak and minimum load of 1500 and $700 \mathrm{MW}$, respectively.

Table 1 Cost Coefficients, Unit Characteristics of 10units system

Table2 Cost Coefficients, Unit Characteristics of 3 units system

\begin{tabular}{|c|c|c|c|c|c|c|c|c|c|c|c|c|}
\hline \multicolumn{2}{|c|}{ Startup costs } & \multirow{2}{*}{$\begin{array}{l}\text { Init. } \\
\text { Unit } \\
\text { status }\end{array}$} & \multirow{2}{*}{$\begin{array}{l}\text { Cold } \\
\text { Start } \\
(\mathrm{Hr})\end{array}$} & \multirow{2}{*}{$\begin{array}{c}\text { Shut } \\
\text { down } \\
\text { Cost } \\
(\$)\end{array}$} & \multirow{2}{*}{$\begin{array}{c}\text { Min } \\
\text { Down } \\
\text { Time } \\
(\mathrm{Hr}) \\
\end{array}$} & \multirow{2}{*}{$\begin{array}{c}\text { Min } \\
\text { Up } \\
\text { Time } \\
(\mathrm{Hr})\end{array}$} & \multirow{2}{*}{$\mathrm{c}$} & \multirow{2}{*}{$\mathrm{b}$} & \multirow{2}{*}{ a } & \multirow{2}{*}{$\begin{array}{l}\text { Min. } \\
\text { MW }\end{array}$} & \multirow{2}{*}{$\begin{array}{l}\text { Max } \\
\text { MW }\end{array}$} & \multirow{2}{*}{$\begin{array}{l}\text { Gen } \\
\text { No }\end{array}$} \\
\hline $\begin{array}{l}\text { Cold } \\
(\$)\end{array}$ & $\begin{array}{l}\text { Hot } \\
(\$)\end{array}$ & & & & & & & & & & & \\
\hline 176 & 70 & -5 & 4 & 50 & 2 & 4 & 500 & 10 & 0.002 & 150 & 600 & 1 \\
\hline 187 & 74 & 8 & 5 & 60 & 3 & 5 & 300 & 08 & 0.0025 & 100 & 400 & 2 \\
\hline 113 & 50 & 8 & 5 & 30 & 1 & 5 & 100 & 06 & 0.005 & 50 & 200 & 3 \\
\hline
\end{tabular}

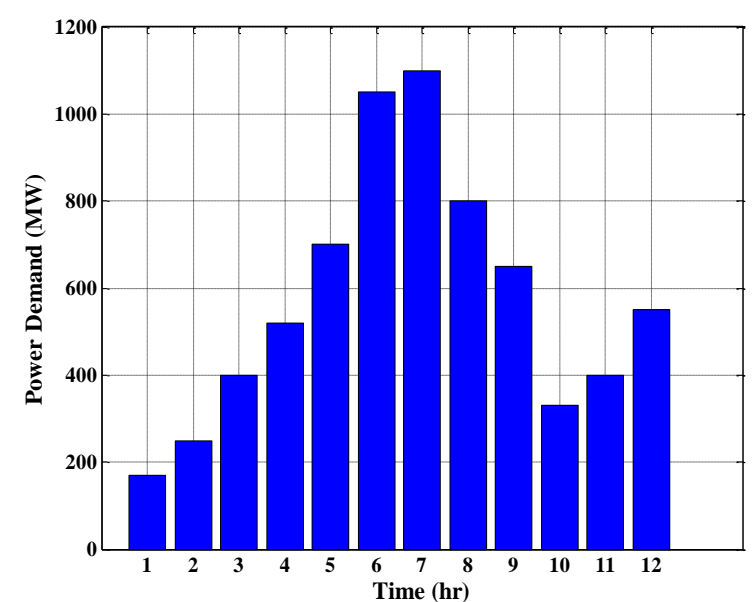

Fig. 3 Load curve of 3 units system 


\begin{tabular}{|c|c|c|c|c|c|c|c|c|c|c|c|}
\hline \multirow{2}{*}{$\begin{array}{c}\text { Gen } \\
\text { No }\end{array}$} & \multirow{2}{*}{$\begin{array}{l}\text { Max } \\
\text { MW }\end{array}$} & \multirow{2}{*}{$\begin{array}{l}\text { Min. } \\
\text { MW }\end{array}$} & \multirow{2}{*}{$\mathrm{a}$} & \multirow{2}{*}{$\mathrm{b}$} & \multirow{2}{*}{ c } & \multirow{2}{*}{$\begin{array}{l}\text { Min } \\
\text { Up } \\
\text { Time } \\
(\mathrm{Hr})\end{array}$} & \multirow{2}{*}{$\begin{array}{c}\text { Min } \\
\text { Down } \\
\text { Time } \\
(\mathrm{Hr})\end{array}$} & \multirow{2}{*}{$\begin{array}{l}\text { Cold } \\
\text { Start } \\
(\mathrm{Hr})\end{array}$} & \multirow{2}{*}{$\begin{array}{c}\text { Init. } \\
\text { unit } \\
\text { status }\end{array}$} & \multicolumn{2}{|c|}{ Startup costs } \\
\hline & & & & & & & & & & $\begin{array}{l}\text { Hot } \\
(\$)\end{array}$ & $\begin{array}{l}\text { Cold } \\
(\$)\end{array}$ \\
\hline 1 & 455 & 150 & 0.00048 & 16.19 & 1000 & 8 & 8 & 5 & 8 & 4500 & 9000 \\
\hline 2 & 455 & 150 & 0.00031 & 17.26 & 970 & 8 & 8 & 5 & 8 & 5000 & 10,000 \\
\hline 3 & 130 & 20 & 0.002 & 16.6 & 700 & 5 & 5 & 4 & -5 & 550 & 1100 \\
\hline 4 & 130 & 20 & 0.00211 & 16.5 & 680 & 5 & 5 & 4 & -5 & 560 & 1120 \\
\hline 5 & 162 & 25 & 0.00398 & 19.7 & 450 & 6 & 6 & 4 & -6 & 900 & 1800 \\
\hline 6 & 80 & 20 & 0.00712 & 22.26 & 370 & 3 & 3 & 2 & -3 & 170 & 340 \\
\hline 7 & 85 & 25 & 0.00079 & 27.74 & 480 & 3 & 3 & 2 & -3 & 260 & 520 \\
\hline 8 & 55 & 10 & 0.00413 & 25.92 & 660 & 1 & 1 & 0 & -1 & 30 & 60 \\
\hline 9 & 55 & 10 & 0.00222 & 27.27 & 665 & 1 & 1 & 0 & -1 & 30 & 60 \\
\hline 10 & 55 & 10 & 0.00173 & 27.79 & 670 & 1 & 1 & 0 & -1 & 30 & 60 \\
\hline
\end{tabular}

Table 3 UC schedule of 3 units 12-hour system

In this paper the data above is used as input to the regular UC

MATLAB program in which the algorithm (PSO) is built in and the output is the obtained results that shown in next section.

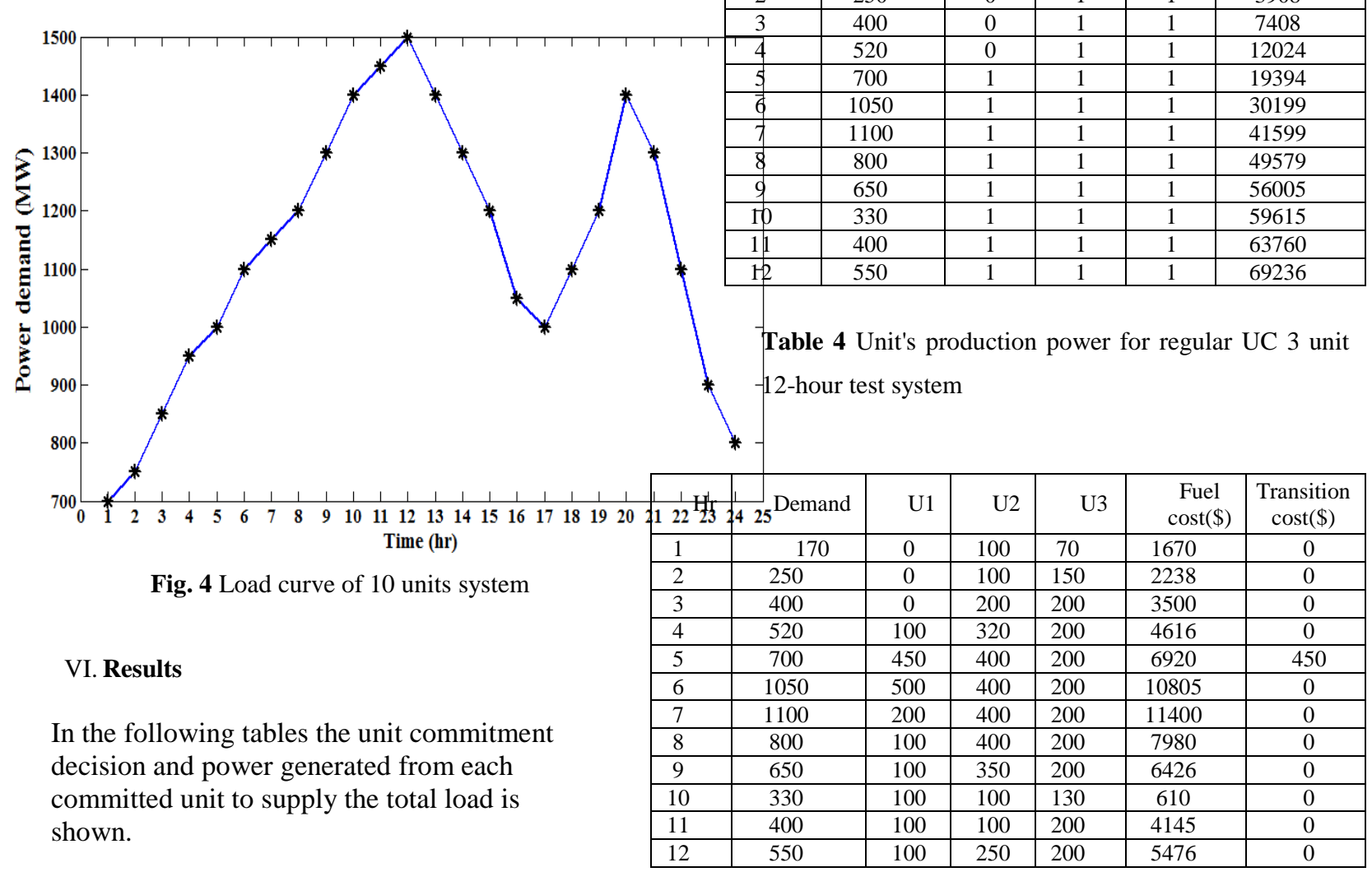


Tables from 3 to 6 show the results of the two case studies which contains the unit's states, the unit's production power and the total cost for regulated

$$
\text { power system. The tables }
$$

from 7 to 9 show the results of the two case studies and contains the units states, the units production power, total cost and the total profit for deregulated power system all this results obtained by particle swarm optimization algorithm (PSO).

Table 5 UC schedule of 10 - units 24-hours system for regular UC

\begin{tabular}{|c|c|c|c|c|c|c|c|c|c|c|c|c|}
\hline \multirow[b]{2}{*}{$\mathrm{Hr}$} & \multirow[b]{2}{*}{$\mathrm{D}(\mathrm{MW})$} & \multicolumn{10}{|c|}{ Unit Number } & \multirow{3}{*}{$\begin{array}{c}\text { Cumulative } \\
\text { Cost }\end{array}$} \\
\hline & & 1 & 2 & 3 & 4 & 5 & 6 & 7 & 8 & 9 & 10 & \\
\hline & 1 state & 1 & 1 & 0 & 0 & 0 & 0 & 0 & 0 & 0 & 0 & \\
\hline 1 & 700 & 1 & 1 & 0 & 0 & 0 & 0 & 0 & 0 & 0 & 0 & 13.683 .13 \\
\hline 2 & 750 & 1 & 1 & 0 & 0 & 0 & 0 & 0 & 0 & 0 & 0 & 28237.63 \\
\hline 3 & 850 & 1 & 1 & 0 & 0 & 1 & 0 & 0 & 0 & 0 & 0 & 45947.08 \\
\hline 4 & 950 & 1 & 1 & 0 & 0 & 1 & 0 & 0 & 0 & 0 & 0 & 64544.75 \\
\hline 5 & 1000 & 1 & 1 & 0 & 1 & 1 & 0 & 0 & 0 & 0 & 0 & 85124.76 \\
\hline 6 & 1100 & 1 & 1 & 1 & 1 & 1 & 0 & 0 & 0 & 0 & 0 & 108611.8 \\
\hline 7 & 1150 & 1 & 1 & 1 & 1 & 1 & 0 & 0 & 0 & 0 & 0 & 131873.8 \\
\hline 8 & 1200 & 1 & 1 & 1 & 1 & 1 & 0 & 0 & 0 & 0 & 0 & 156024.1 \\
\hline 9 & 1300 & 1 & 1 & 1 & 1 & 1 & 1 & 1 & 0 & 0 & 0 & 184135.2 \\
\hline 10 & 1400 & 1 & 1 & 1 & 1 & 1 & 1 & 1 & 1 & 0 & 0 & 214252.7 \\
\hline 11 & 1450 & 1 & 1 & 1 & 1 & 1 & 1 & 1 & 1 & 1 & 0 & 246228.8 \\
\hline 12 & 1500 & 1 & 1 & 1 & 1 & 1 & 1 & 1 & 1 & 1 & 1 & 280179 \\
\hline 13 & 1400 & 1 & 1 & 1 & 1 & 1 & 1 & 1 & 1 & 0 & 0 & 310236.5 \\
\hline 14 & 1300 & 1 & 1 & 1 & 1 & 1 & 1 & 1 & 0 & 0 & 0 & 337487.6 \\
\hline 15 & 1200 & 1 & 1 & 1 & 1 & 1 & 0 & 0 & 0 & 0 & 0 & 361637.9 \\
\hline 16 & 1050 & 1 & 1 & 1 & 1 & 1 & 0 & 0 & 0 & 0 & 0 & 383151.6 \\
\hline 17 & 1000 & 1 & 1 & 1 & 1 & 1 & 0 & 0 & 0 & 0 & 0 & 403793.4 \\
\hline 18 & 1100 & 1 & 1 & 1 & 1 & 1 & 0 & 0 & 0 & 0 & 0 & 426180.4 \\
\hline 19 & 1200 & 1 & 1 & 1 & 1 & 1 & 0 & 0 & 0 & 0 & 0 & 450330.8 \\
\hline 20 & 1400 & 1 & 1 & 1 & 1 & 1 & 1 & 1 & 1 & 0 & 0 & 480878.3 \\
\hline 21 & 1300 & 1 & 1 & 1 & 1 & 1 & 1 & 1 & 0 & 0 & 0 & 508129.4 \\
\hline 22 & 1100 & 1 & 1 & 0 & 0 & 1 & 1 & 1 & 0 & 0 & 0 & 530864.9 \\
\hline 23 & 900 & 1 & 1 & 0 & 0 & 0 & 1 & 0 & 0 & 0 & 0 & 548510.3 \\
\hline 24 & 800 & 1 & 1 & 0 & 0 & 0 & 0 & 0 & 0 & 0 & 0 & 563937.7 \\
\hline
\end{tabular}

Table 6 Unit's production power for regular UC of 10 - units 24-hours system

\begin{tabular}{|c|c|c|c|c|c|c|c|c|c|c|c|c|c|}
\hline \multirow[b]{2}{*}{$\mathrm{Hr}$} & \multirow[b]{2}{*}{$\mathrm{D}(\mathrm{MW})$} & \multicolumn{10}{|c|}{ Unit Number } & \multirow[b]{2}{*}{ Cost } & \multirow{2}{*}{$\begin{array}{l}\text { transition } \\
\text { Cost }\end{array}$} \\
\hline & & 1 & 2 & 3 & 4 & 5 & 6 & 7 & 8 & 9 & 10 & & \\
\hline 1 & 700 & 455 & 245 & 0 & 0 & 0 & 0 & 0 & 0 & 0 & 0 & 13683.13 & 0 \\
\hline 2 & 750 & 455 & 295 & 0 & 0 & 0 & 0 & 0 & 0 & 0 & 0 & 14554.5 & 0 \\
\hline 3 & 850 & 455 & 370 & 0 & 0 & 25 & 0 & 0 & 0 & 0 & 0 & 16809.45 & 900 \\
\hline 4 & 950 & 455 & 455 & 0 & 0 & 40 & 0 & 0 & 0 & 0 & 0 & 18597.67 & 0 \\
\hline 5 & 1000 & 455 & 390 & 0 & 130 & 25 & 0 & 0 & 0 & 0 & 0 & 20020.01 & 560 \\
\hline 6 & 1100 & 455 & 360 & 130 & 130 & 25 & 0 & 0 & 0 & 0 & 0 & 22387.05 & 1100 \\
\hline 7 & 1150 & 455 & 410 & 130 & 130 & 25 & 0 & 0 & 0 & 0 & 0 & 23261.98 & 0 \\
\hline 8 & 1200 & 455 & 455 & 130 & 130 & 30 & 0 & 0 & 0 & 0 & 0 & 24150.34 & 0 \\
\hline 9 & 1300 & 455 & 455 & 130 & 130 & 85 & 20 & 25 & 0 & 0 & 0 & 27251.06 & 860 \\
\hline 10 & 1400 & 455 & 455 & 130 & 130 & 162 & 33 & 25 & 10 & 0 & 0 & 30057.55 & 60 \\
\hline 11 & 1450 & 455 & 455 & 130 & 130 & 162 & 73 & 25 & 10 & 10 & 0 & 31916.06 & 60 \\
\hline 12 & 1500 & 455 & 455 & 130 & 130 & 162 & 80 & 25 & 43 & 10 & 10 & 33890.16 & 60 \\
\hline 13 & 1400 & 455 & 455 & 130 & 130 & 162 & 33 & 25 & 10 & 0 & 0 & 30057.55 & 0 \\
\hline 14 & 1300 & 455 & 455 & 130 & 130 & 85 & 20 & 25 & 0 & 0 & 0 & 27251.06 & 0 \\
\hline 15 & 1200 & 455 & 455 & 130 & 130 & 30 & 0 & 0 & 0 & 0 & 0 & 24150.34 & 0 \\
\hline 16 & 1050 & 455 & 310 & 130 & 130 & 25 & 0 & 0 & 0 & 0 & 0 & 21513.66 & 0 \\
\hline 17 & 1000 & 455 & 260 & 130 & 130 & 25 & 0 & 0 & 0 & 0 & 0 & 20641.82 & 0 \\
\hline 18 & 1100 & 455 & 360 & 130 & 130 & 25 & 0 & 0 & 0 & 0 & 0 & 22387.04 & 0 \\
\hline 19 & 1200 & 455 & 455 & 130 & 130 & 30 & 0 & 0 & 0 & 0 & 0 & 24150.34 & 0 \\
\hline 20 & 1400 & 455 & 455 & 130 & 130 & 162 & 33 & 25 & 10 & 0 & 0 & 30057.55 & 490 \\
\hline 21 & 1300 & 455 & 455 & 130 & 130 & 85 & 20 & 25 & 0 & 0 & 0 & 27251.06 & 0 \\
\hline 22 & 1100 & 455 & 455 & 0 & 0 & 145 & 20 & 25 & 0 & 0 & 0 & 22735.52 & 0 \\
\hline 23 & 900 & 455 & 455 & 0 & 0 & 0 & 20 & 0 & 0 & 0 & 0 & 17645.36 & 0 \\
\hline 24 & 800 & 455 & 345 & 0 & 0 & 0 & 0 & 0 & 0 & 0 & 0 & 15427.42 & 0 \\
\hline
\end{tabular}


Sahar.S.Kaddah, Ragab.A. Elsehiemy, Alaa .A. Zaky "Solving Unit Commitment ......."

Table 7 Power and reserve generation for 3 units test system for profit- based unit commitment

\begin{tabular}{|c|c|c|c|c|c|c|c|c|c|c|}
\hline \multirow[b]{3}{*}{$\mathrm{Hr}$} & \multirow{3}{*}{$\begin{array}{c}\mathrm{D} \\
(\mathrm{MW})\end{array}$} & \multicolumn{3}{|c|}{ Power (MW) } & \multicolumn{3}{|c|}{ Reserve (MW) } & \multirow{3}{*}{$\begin{array}{c}\text { Fuel } \\
\operatorname{cost}(\$)\end{array}$} & \multirow{3}{*}{$\begin{array}{c}\text { Trans } \\
\operatorname{cost}(\$)\end{array}$} & \multirow{3}{*}{$\begin{array}{l}\text { Profit } \\
(\$)\end{array}$} \\
\hline & & \multicolumn{3}{|c|}{ unit } & \multicolumn{3}{|c|}{ unit } & & & \\
\hline & & 1 & 2 & 3 & 1 & 2 & 3 & & & \\
\hline 1 & 170 & 0 & 0 & 170 & 0 & 0 & 20 & 1265.3 & 0 & 537.7 \\
\hline 2 & 250 & 0 & 0 & 200 & 0 & 0 & 0 & 1500 & 0 & 570 \\
\hline 3 & 400 & 0 & 0 & 200 & 0 & 0 & 0 & 1500 & 0 & 300 \\
\hline 4 & 520 & 0 & 0 & 200 & 0 & 0 & 0 & 1500 & 0 & 390 \\
\hline 5 & 700 & 0 & 330 & 200 & 0 & 70 & 0 & 4715.8 & 400 & 215.7 \\
\hline 6 & 1050 & 0 & 400 & 200 & 0 & 0 & 0 & 5400 & 0 & 1350 \\
\hline 7 & 1100 & 0 & 400 & 200 & 0 & 0 & 0 & 5400 & 0 & 1380 \\
\hline 8 & 800 & 0 & 400 & 200 & 0 & 0 & 0 & 5400 & 0 & 990 \\
\hline 9 & 650 & 0 & 387.2 & 200 & 0 & 12.2 & 0 & 5273.1 & 0 & 810 \\
\hline 10 & 330 & 0 & 130 & 200 & 0 & 35 & 0 & 2883.8 & 0 & 829.8 \\
\hline 11 & 400 & 0 & 200 & 200 & 0 & 40 & 0 & 3501.8 & 0 & 817.4 \\
\hline 12 & 550 & 0 & 350 & 200 & 0 & 50 & 0 & 4908.4 & 0 & 945 \\
\hline
\end{tabular}

Table 8 UC schedule of 10 - units 24 hours test system for profit- based UC

\begin{tabular}{|c|c|c|c|c|c|c|c|c|c|}
\hline \multirow[t]{2}{*}{$\mathrm{Hr}$} & \multicolumn{7}{|c|}{$\begin{array}{c}\text { Unit } \\
\text { Number }\end{array}$} & \multirow{2}{*}{$\begin{array}{c}\text { Cumulative } \\
\text { Cost (\$). }\end{array}$} & \multirow{2}{*}{$\begin{array}{c}\text { Cumulative } \\
\text { Profit (\$) }\end{array}$} \\
\hline & 1 & 2 & 3 & 4 & 5 & 6 & $7-10$ & & \\
\hline 1 & 1 & 1 & 0 & 0 & 0 & 0 & 0 & 13689.23 & 1838.948 \\
\hline 2 & 1 & 1 & 0 & 0 & 0 & 0 & 0 & 28250.28 & 3802.566 \\
\hline 3 & 1 & 1 & 0 & 0 & 0 & 0 & 0 & 44557.43 & 7151.14 \\
\hline 4 & 1 & 1 & 0 & 0 & 0 & 0 & 0 & 6191073 & 10409.34 \\
\hline 5 & 1 & 1 & 0 & 0 & 0 & 0 & 0 & 7926403 & 14213.54 \\
\hline 6 & 1 & 1 & 0 & 1 & 0 & 0 & 0 & 100038 & 1730758 \\
\hline 7 & 1 & 1 & 0 & 1 & 0 & 0 & 0 & 120251.9 & 20493.62 \\
\hline 8 & 1 & 1 & 0 & 1 & 0 & 0 & 0 & 140465.9 & 2331.66 \\
\hline 9 & 1 & 1 & 1 & 1 & 0 & 0 & 0 & 164121.7 & 2633.91 \\
\hline 10 & 1 & 1 & 1 & 1 & 1 & 0 & 0 & 193959.9 & 37587.69 \\
\hline 11 & 1 & 1 & 1 & 1 & 1 & 0 & 0 & 2230079 & 51111.52 \\
\hline 12 & 1 & 1 & 1 & 1 & 1 & 0 & 0 & 25055.8 & 66753.34 \\
\hline 13 & 1 & 1 & 1 & 1 & 1 & 1 & 0 & 278907.4 & 72668.93 \\
\hline 14 & 1 & 1 & 1 & 1 & 1 & 1 & 0 & 305094.2 & 78343.89 \\
\hline 15 & 1 & 1 & 0 & 1 & 1 & 1 & 0 & 329012.2 & 81426.54 \\
\hline 16 & 1 & 1 & 0 & 1 & 0 & 0 & 0 & 349226.2 & 844059 \\
\hline 17 & 1 & 1 & 0 & 1 & 0 & 0 & 0 & 369440.1 & 87330.63 \\
\hline 18 & 1 & 1 & 0 & 1 & 0 & 0 & 0 & $\begin{array}{l}389654.1 \\
\end{array}$ & 90048.67 \\
\hline 19 & 1 & 1 & 0 & 1 & 0 & 0 & 0 & 409868.1 & 92922.71 \\
\hline 20 & 1 & 1 & 0 & 1 & 0 & 0 & 0 & 430082 & 96264.75 \\
\hline 21 & 1 & 1 & 0 & 1 & 0 & 0 & 0 & 450296 & 100074.8 \\
\hline 22 & 1 & 1 & 0 & 1 & 0 & 0 & 0 & 470509.9 & 103728.8 \\
\hline 23 & 1 & 1 & 0 & 0 & 0 & 0 & 0 & 487688.7 & 1072028.4 \\
\hline 24 & 1 & 1 & 0 & 0 & 0 & 0 & 0 & 503123.1 & 109661 \\
\hline
\end{tabular}

Table 9 power and reserve generation for 10- units system for profit- based UC

\begin{tabular}{|c|c|c|c|c|c|c|c|c|c|c|c|c|c|c|c|}
\hline $\mathrm{Hr}$ & \multicolumn{7}{|c|}{ Power (MW) } & \multicolumn{5}{|c|}{ Reserve } & \multirow{2}{*}{$\begin{array}{l}\text { Fuel cost } \\
\text { (\$) }\end{array}$} & \multirow{2}{*}{$\begin{array}{c}\text { Transition } \\
\operatorname{cost}(\$)\end{array}$} & \multirow[b]{2}{*}{ Profit (\$) } \\
\hline 1 & 1 & 2 & 3 & 4 & 5 & 6 & $7-10$ & 1 & 2 & $3-4$ & 5 & $\begin{array}{l}6- \\
10\end{array}$ & & & \\
\hline 2 & 455 & 245 & 0 & 0 & 0 & 0 & 0 & 0 & 70 & 0 & 0 & 0 & 13689.23 & 0 & 1838.958 \\
\hline 3 & 455 & 295 & 0 & 0 & 0 & 0 & 0 & 0 & 75 & 0 & 0 & 0 & 14561.15 & 0 & 1963.618 \\
\hline 4 & 455 & 395 & 0 & 0 & 0 & 0 & 0 & 0 & 60 & 0 & 0 & 0 & 16307.2 & 0 & 3348.574 \\
\hline 5 & 455 & 455 & 0 & 0 & 0 & 0 & 0 & 0 & 0 & 0 & 0 & 0 & 17353.3 & 0 & 3258.2 \\
\hline 6 & 455 & 455 & 0 & 130.0 & 0 & 0 & 0 & 0 & 0 & 0 & 0 & 0 & 17353.3 & 0 & 3804.2 \\
\hline 7 & 455 & 455 & 0 & 130.0 & 0 & 0 & 0 & 0 & 0 & 0 & 0 & 0 & 20213.96 & 560 & 3094041 \\
\hline 8 & 455 & 455 & 0 & 130.0 & 0 & 0 & 0 & 0 & 0 & 0 & 0 & 0 & 20213.96 & 0 & 3186.041 \\
\hline 9 & 455 & 455 & 130.0 & 130.0 & 0 & 0 & 0 & 0 & 0 & 0 & 0 & 0 & 20213.96 & 0 & 2822.041 \\
\hline 10 & 455 & 455 & 130.0 & 130.0 & 162 & 68 & 0 & 0 & 0 & 0 & 0 & 0 & 20213.96 & 550 & 3020.241 \\
\hline 11 & 455 & 455 & 130.0 & 130.0 & 162 & 80 & 0 & 0 & 0 & 0 & 0 & 0 & 28768.21 & 1070 & 11251.79 \\
\hline 12 & 455 & 455 & 130.0 & 130.0 & 162 & 80 & 0 & 0 & 0 & 0 & 0 & 0 & 29047.98 & 0 & 13523.82 \\
\hline 13 & 455 & 455 & 130.0 & 130.0 & 162 & 0 & 0 & 0 & 0 & 0 & 0 & 0 & 29047.98 & 0 & 15641.82 \\
\hline 14 & 455 & 455 & 130.0 & 130.0 & 130 & 0 & 0 & 0 & 0 & 0 & 32 & 0 & 26851.61 & 0 & 5915.59 \\
\hline 15 & 455 & 455 & 0 & 130.0 & 160 & 0 & 0 & 0 & 0 & 0 & 2 & 0 & 26186.76 & 0 & 5674.961 \\
\hline 16 & 455 & 455 & 0 & 130.0 & 0 & 0 & 0 & 0 & 0 & 0 & 0 & 0 & 23918.02 & 0 & 3082.655 \\
\hline 17 & 455 & 455 & 0 & 130.0 & 0 & 0 & 0 & 0 & 0 & 0 & 0 & 0 & 23918.02 & 0 & 2978.041 \\
\hline 18 & 455 & 455 & 0 & 130.0 & 0 & 0 & 0 & 0 & 0 & 0 & 0 & 0 & 20213.96 & 0 & 2978.041 \\
\hline 19 & 455 & 455 & 0 & 130.0 & 0 & 0 & 0 & 0 & 0 & 0 & 0 & 0 & 20213.96 & 0 & 2718.041 \\
\hline 20 & 455 & 455 & 0 & 130.0 & 0 & 0 & 0 & 0 & 0 & 0 & 0 & 0 & 2021396 & 0 & 3342.041 \\
\hline 21 & 455 & 455 & 0 & 130.0 & 0 & 0 & 0 & 0 & 0 & 0 & 0 & 0 & 2021396 & 0 & 3810.041 \\
\hline 22 & 455 & 455 & 0 & 130.0 & 0 & 0 & 0 & 0 & 0 & 0 & 0 & 0 & 2021396 & 0 & 3654.041 \\
\hline 23 & 455 & 455 & 0 & 0 & 0 & 0 & 0 & 0 & 10 & 0 & 0 & 0 & 17178.79 & 0 & 3299.614 \\
\hline 24 & 455 & 345 & 0 & 0 & 0 & 0 & 0 & 0 & 80 & 0 & 0 & 0 & 15434.42 & 0 & 2632.551 \\
\hline
\end{tabular}


Sahar.S.Kaddah, Ragab.A. Elsehiemy, Alaa .A. Zaky "Solving Unit Commitment ......."

Table 10 comparison between different approaches for regular UC

(10-units system)

\begin{tabular}{|c|c|c|}
\hline & \multicolumn{2}{|c|}{ Cost based UC } \\
\hline Method & Cost $(\$)$ & CPU (sec) \\
\hline Proposed approach & 563937.7 & 31 \\
\hline LR [31 ] & 564892 & 120 \\
\hline GA [32 ] & 565825 & 221 \\
\hline EP [33 ] & 564551 & 100 \\
\hline LRGA [34 ] & 564800 & 518 \\
\hline
\end{tabular}

Table 10 and 11 shows a comparison between different approaches for the total production cost and computing time (CPU).The proposed approach is the best method in which as minimum generation costs and computational time in regular UC and maximum profit for

\begin{tabular}{|c|c|c|c|}
\hline & \multicolumn{3}{|c|}{ PBUC } \\
\hline Method & Cost (\$) & Profit(\$) & CPU (sec) \\
\hline Proposed approach & 503123.1 & 109661 & 31 \\
\hline LR- EP [35] & - & 107838.57 & - \\
\hline Multi-Agent [36] & - & 109485.19 & 80 \\
\hline Traditional & 563169.64 & 89184.18 & - \\
\hline
\end{tabular}

profit based (deregulation) UC compared to the other approaches.

\section{CONCOLUSIONS}

This paper concludes that the proposed PSO algorithm can be applied to solve both traditional and profit based unit commitment problem in the deregulated power system environment. The performance of the proposed PSO algorithm when compared with the existing literature methods is found to be encouraging where a significant amount of profit can be achieved for the GENCOs. This method is simple, robust and is suit- able for GENCOs in a power market. Though PSO can be applied for large scale power system, it has the limitation on convergence similar to other random and stochastic algorithms like GA, ant colony, evolutionary programming, etc. The results signify that PSO is very much suitable for larger power system with more number of generating units.

\section{REFERENCES}

[1] Kerr R. H, Scheidt JL, Fontana AJ, Wiley JK. Unit commitment. IEEE Trans Power Apparatus Syst 1966;85(5):417.

[2] Yamin HY. Review on methods of generation scheduling in electric power systems. EPSR 2004;69:227.

[3] R. H. Kerr, J. L. Scheidt, A. J. Fontana, and J. K. Wiley, "Unit commitment," IEEE Trans. Power App. Syst., vol. PAS-85, pp. 417-421, May 1966.
[4] K. Hara, M. Kimura, and N. Honda, "A method for planning economic unit commitment and maintenance of thermal power systems," IEEE Trans. Power App. Syst., vol. PAS-85, pp. 427-436, May 1966.

[5] K. Ayoub and A. D. Patton, "Optimal thermal generating unit commitment," IEEE Trans. Power App. Syst., vol. PAS-90, pp. 1752-1756, July/Aug. 1971

[6] C. K. Pang and H. C. Chen, "Optimal short-term thermal unit commitment," IEEE Trans. Power App. Syst., vol. PAS-95, pp. 1336-1346, July/Aug. 1976.

[7] Burns, R.M., and Gibson, C.A., (1975), "Optimization of Priority Lists for a Unit Commitment Program", Proc. of IEEE Power Engg. Society Summer Meeting.

[8] Sheble, G.B.,(1990), "Solution of the Unit Commitment Problem by the method of Unit Periods", IEEE Trans. On Power Systems, 5, (1), pp. 257-260.

[9] Dillon, T.S., and Edwin, K.W., (1978), "Integer Programming Approach to the Problem of Optimal Unit Commitment with Probabilistic Reserve Determination", IEEE Trans. On Power Systems, 97, (6), pp. 2154-2166.

[10] Garver, L.L., (1963), "Power Generation Scheduling by Integer Programming- Development of Theory", IEEE Trans. On power Systems, 102, pp. 730-735.

[11] Synder, W.L.Jr., Powell, H.D.Jr., and Rayburn, J.C., "Dynamic Programming Approach to Unit Commitment”, IEEE Trans. On Power Systems, 2, pp. 339-350.

[12] Wood, A.J., and Wollenberg, B.F., (1996) "Power Generation, Operation and Control", John Wiley \& sons, Inc.

[13] Lowery, P.G., (1983), “Generation Unit Commitment by Dynamic Programming", IEEE Trans. On Power Systems, 102, pp. 1218-1225.

[14] Ouyang, Z., and Shahidehpour, S.M., (1991), “An Intelligent Dynamic Programming for Unit Commitment Application", IEEE Trans. On Power Systems, 6, (3), pp. 1203-1209.

[15] Cohen, A.I., and Yoshimura, M., (1983), “A Branch and Bound Algorithm for Unit Commitment”, IEEE Trans. On Power Systems, 102, (2), pp. 444-451.

[16]Zhao B, Guo CX, Bai BR, Cao YJ. An improved particle swarm optimization algorithm for unit commitment. EPES 2006;28:482.

[17] Ting TO, Rao MVC, Loo CK. A novel approach for unit commitment problem via an effective hybrid particle swarm optimization. IEEE Trans Power Syst 2006;21(1):411. 
Sahar.S.Kaddah, Ragab.A. Elsehiemy, Alaa .A. Zaky "Solving Unit Commitment ......."

[18] Sun L, Zhang Y, Jiang C. A matrix real-coded genetic algorithm to the unit commitment problem. EPSR 2006;76:716.

[19] Arroyo JM, Conejo AJ. A parallel repair genetic algorithm to solve the unit commitment problem. IEEE Trans Power Syst 2002;17(4):1216.

[20]F. Zhuang and F. D. Galiana, "Unit Commitment by Simulated

Annealing," IEEE Trans. on Power Systems, vol. 5, no. 1, pp. 311-317,1990.

[21] Simon SP, Padhy NP, Anand RS. An ant colony system approach for unit commitment problem. EPES 2006;28:315.

[22] Rajan CCA, Mohan MR. An evolutionary programming based Tabu search method for solving the unit commitment problem. IEEE Trans Power Syst 2004;19(1):577.

[23] Padhy, N.P.(2004), "Unit Commitment- A Bibliographical Survey”, IEEE Trans. On Power Systems, 19, (2), pp.1196-1205.

[24] Yong Fu, and Mohammad Shahidehpour., (2005), "Security Constrained Unit Commitment with AC Constraints", IEEE Trans. On Power Systems, 20, (2), pp. 1001-1013.

[25] "Promoting Wholesale Competition Through Open Access Non-discriminatory Transmission Services by Public Utilities." Federal Energy Regulatory Commission Order No. 888, 1996.

[26]F.D. Galiana and M.D. Ilic. A mathematical framework for the analysis and management of power transactions under open access. IEEE Transactions on Power Systems, 13: 681-687, 1998.

[27] Market rules for the Ontario Electricity Market, issue date. Available from: http://www.ieso.ca/imoweb/pubs/marketRules/mr marketRules.pdf, (accessed March 2011).

[28] B.K. Pokharel, G.B. Shrestha, T.T. Lie, S.E. Fleten, Price based unit commitment for Gencos in deregulated markets, in: Power Engineering Society General Meeting, 2005, pp. 428-434.

[29] Introduction to the National Electricity Market of Singapore,

version.6.Availablefrom:http://www.ema.gov.sg/me dia/files/books/intro to nems.pdf, 2010 (accessed March 2011).

[30] S. virmani, k. Imhof, s. Mukherjee, "Implementation of algrangian relaxation based unit commitment problem ," IEEE Transactions on power system ,Vol. 4,No. 4, pp. 1373 - 1379, October 1989.

[31]F. Benhamida, "A Short-term Unit Commitment Solution using Lagrangian Relaxation Method ," Ph.D. Thesis, Alexandria University ,Egypt , October 2006.

[32] S.A.Kazarlis,A.G.Bakirtzs, and V. Petridis, "genetic algorithm solution to the unit commitment problem ,IEEE Transactions on Power Systems ,Vol. 11,No. 1, PP. 83-92,February 1996.

[33]C.C. Rajan, M. R. Mohan, "An Evolutionary Programming -Based Tabu Search Method for Solving The Unit Commitment Problem ,"IEEE Transactions on Power Systems, Vol. 19,No. 1,PP. 577-585, February 2004.

[34] C.P. Cheng, C. W. Liu and C.C. Liu, "Unit Commitment by Lagrngian Relaxation and Genatic Algorithms," IEEE Transactions on power systems , Vol. 15,No. 2,pp. 707-714,May2000.

[35] P. Attaviriyanupap, H. Kita, E. Tanaka, J. Hasegawa, "A Hybrid LR-EP for Solving New Profit-Based UC Problem under Competitive Environment ," IEEE Transactions on power systems, Vol. 18, No. 1, pp. 229-237, February 2003.

[36] J.J Zhou, W. Wu, J. Yang, and W. Yu, "Solution of The Profit -Based Unit Commitment Problem by Using Multi-Agent System," Proceedings of the $5^{\text {th }}$ World Congress on Intelligent Control and Automation, Vol. 15, No. 19. pp. 5079-5083, June 2004. 